\title{
UNBIASED ESTIMATION OF NORWAY SPRUCE (PICEA ABIES L. KARST.) CHLOROPLAST STRUCTURE: HETEROGENEITY WITHIN NEEDLE MESOPHYLL UNDER DIFFERENT IRRADIANCE AND $\left[\mathrm{CO}_{2}\right]$
}

\author{
ZuZANA KuBÍNOVÁ ${ }^{1}$, NATÁlia GLANC ${ }^{1}$, BARBORA RADOCHOVÁ ${ }^{1,2}$, ZuZANA LHOTÁKOVÁ ${ }^{1}$, \\ JiŘí JANÁČEK ${ }^{2}$, LUCIE KUBÍNOVÁ ${ }^{2}$, JANA ALBRECHTOVÁ ${ }^{\bowtie, 1}$ \\ ${ }^{1}$ Department of Experimental Plant Biology, Faculty of Science, Charles University, Viničná 5, 12844 Prague \\ 2, Czech Republic; ${ }^{2}$ Department of Biomathematics, Institute of Physiology of the Czech Academy of Sciences, \\ Vídeňská 1083, 14220 Prague 4, Czech Republic \\ e-mails: kubinova@natur.cuni.cz,glanc.nat@gmail.com,barbora.radochova@fgu.cas.cz, \\ zuzana.lhotakova@natur.cuni.cz, jiri.janacek@fgu.cas.cz,lucie.kubinova@fgu.cas.cz, \\ jana.albrechtova@natur.cuni.cz. \\ (Received August 29, 2018; revised January 25, 2019; accepted February 11, 2019)
}

\begin{abstract}
The main objective of this study was to find out whether the selected chloroplast characteristics measured in the mesophyll layer nearest to the needle surface (i.e., the first mesophyll layer) could be representative for the whole needle cross section. Two chloroplast sampling approaches were applied on Norway spruce needles during the investigation of the effects of different levels of air $\mathrm{CO}_{2}$ concentration and irradiance: (i) sampling only from the first mesophyll layer, and (ii) systematic uniform random (SUR) sampling. The selected characteristics were: (i) chloroplast area, (ii) starch grain area, and (iii) starch areal density on median chloroplast cross sections, and (iv) chloroplast number per unit of needle volume. It was shown that the first mesophyll layer was not representative for estimating all evaluated characteristics except the chloroplast area. Sampling only there caused obtaining slightly biased results, while SUR sampling gave unbiased estimations at the cost of longer measuring time. The major effect of studied factors was in starch areal density and starch grain area, which were larger in sun needles in elevated $\mathrm{CO}_{2}$ concentration in comparison with sun needles in ambient $\mathrm{CO}_{2}$ concentration. In conclusion, it was demonstrated that the first layer of mesophyll is not always representative for the needle cross section. If technically feasible, SUR is recommended for analysis of chloroplast ultrastructure. The simplified sampling design can be applied, e.g., for comparisons of many different treatments. However, it should be combined with other approaches to characterize the chloroplast function and the results carefully considered and interpreted.
\end{abstract}

Keywords: chloroplast number, chloroplast ultrastructure, elevated $\mathrm{CO}_{2}$, needle anatomy, stereology.

\section{INTRODUCTION}

Chloroplasts are the photosynthetic organelles of plant cells. They absorb solar energy to run carbon fixation, during which the carbon from $\mathrm{CO}_{2}$ is built into organic compounds. The atmospheric concentration of $\mathrm{CO}_{2}$ is ever increasing (ESRL, 2018); therefore, the global carbon cycling process is affected. Forest trees significantly participate in carbon cycling representing an important carbon sink (rev. Calfapietra et al., 2010). One such important species is the Norway spruce (Picea abies L. Karst.), currently the most abundant conifer in Central European forests. Due to its importance and abundance, appropriate approaches to study its responses to environmental factors, including changes of chloroplast structural characteristics, are of great importance.
Trees are known to accommodate their growth based on sink prioritization in response to environmental factors (Polák et al., 2006). Under elevated $\mathrm{CO}_{2}$ concentration (EC), plants may invest the extra carbon to their growth or to the production of secondary metabolites (Gebauer et al., 1997; Räisänen et al., 2008). Moreover, as a result of EC, leaf anatomy (Lin et al., 2001; Eguchi et al., 2004) and chloroplast ultrastructure (Pritchard et al., 1997; Sallas et al., 2003; Günthardt-Goerg and Vollenweider, 2015) may change. Nevertheless, the effect of $\mathrm{CO}_{2}$ on mesophyll structural characteristics and phenolics accumulation can be ambiguous, as Lhotáková et al. (2012) found no change, even though enhanced light-saturated $\mathrm{CO}_{2}$ assimilation rates and reduced dark respiration in the current-year needles were observed. Irradiance is apparently a stronger morphogenetic factor than EC, 
principally affecting needle differentiation and phenolics content (Lhotáková et al., 2012), and needle shape even within an irradiance gradient on a shoot (Kubínová et al., 2018).

Thus, to study the chloroplast ultrastructure and its quantitative characteristics, careful consideration should be taken concerning the methods applied, including relevant chloroplast sampling for measure-ments, so as to yield unbiased estimations of the observed characteristics.

Chloroplasts can be easily detected using light microscopy; however, its resolution is insufficient for observation of their ultrastructure. Chloroplast ultrastructure, including starch grain cross-section area and the arrangement of the thylakoid membrane system is usually studied on images acquired by transmission electron microscopy (TEM). Because it is difficult to obtain series of ultrathin sections, the studies are usually done on single TEM sections (e.g., Albertsson and Andreasson, 2004; Kubínová and Kutík, 2007; Demmig-Adams et al., 2015). The comparability of 3D characteristics estimated on 2D cross sections between samples is usually ensured by analysing only those chloroplasts that are sectioned in the middle perpendicularly to the prevailing plane of thylakoid membranes, i.e., in their median cross section (FIG 1C, D; Sharkova and Bubolo, 1996; Kutík et al., 2004).

For chloroplast ultrastructural studies in broad leaves, the first or upper layers of leaf photosynthetic tissue, mesophyll, (Fig. 1A) are often analysed (Günthardt-Goerg et al., 2000; Wheeler and Fagerberg 2000; Valkama et al., 2003; Velikova et al., 2009; Sun et al., 2011; Mašková et al., 2017). The first layer of mesophyll receives more incident irradiance than its deeper layers and thus, it can be regarded as the most important layer for photosynthesis. This is also true for conifer needles, where the chloroplast ultrastructure in the outermost mesophyll layer was found to be the most affected by the environmental factors (Anttonen, 1992; Kivimäenpää et al., 2005). Many studies of conifer needle ultrastructure do not specify in detail the part of the needle or the place on needle cross section used for measurements (Palomäki et al., 1996; Pritchard et al., 1997; Kainulainen et al., 2000; Lepeduš et al., 2001; Demmig-Adams et al., 2015). Depending on the type of study, chloroplasts are sampled only from one part of a needle (Utriainen et al., 2000; Jönsson et al., 2001; Sallas et al., 2003; Siefermann-Harms et al., 2004) or from the sun-exposed side of a needle and the mesophyll layer closest to the centre of a needle (Soikkeli, 1978; Wulff et al., 1996; Kivimäenpää 2003; Kivimäenpää et al., 2014).

In order to quantify leaf structure, it is necessary to be aware of possible heterogeneity within the leaf and existing leaf anatomic gradients. A gradient in both irradiance and carbon dioxide concentration is known to exist inside the broad leaves (Parkhust et al., 1988; Smith et al., 1997) and irradiance gradient was also recorded within the needle (DeLucia et al., 1992). In our previous study, we observed a gradient in Norway spruce needle section shape based on the irradiance microgradient within a shoot due to selfshading of needles (Kubínová et al., 2018). It is probable that irradiance microgradient within a needle affects the chloroplast ultrastructure. However, information about the heterogeneity of chloroplast characteristics within needles is still scarce. For example, it was shown that chloroplast alterations caused by ozone are more pronounced in the outer mesophyll cell layers and in the upper side of the needle compared to the inner mesophyll layers and lower side of the needle (Kivimaënpää et al., 2005). This information is essential for proper sampling design for quantitative studies where the absolute values for the whole leaf are needed. As far as we know, no study has yet systematically tested different parts of Norway spruce mesophyll in the sense of representativeness for the whole needle cross section.

In the present study, we focused on methodical and ecophysiological aims. The methodical aim was to test the assumption of the first mesophyll layer representativeness for the whole needle cross section regarding four selected chloroplast characteristics: chloroplast density in mesophyll, chloroplast size, starch grain area and starch areal density. We have compared characteristics of chloroplasts selected within the cells in the first mesophyll layer and cells from systematically uniform randomly selected positions within the mesophyll. The ecophysiological aim was to test whether the selected chloroplast characteristics are influenced by $\mathrm{CO}_{2}$ concentration and irradiance, and to what extent. 

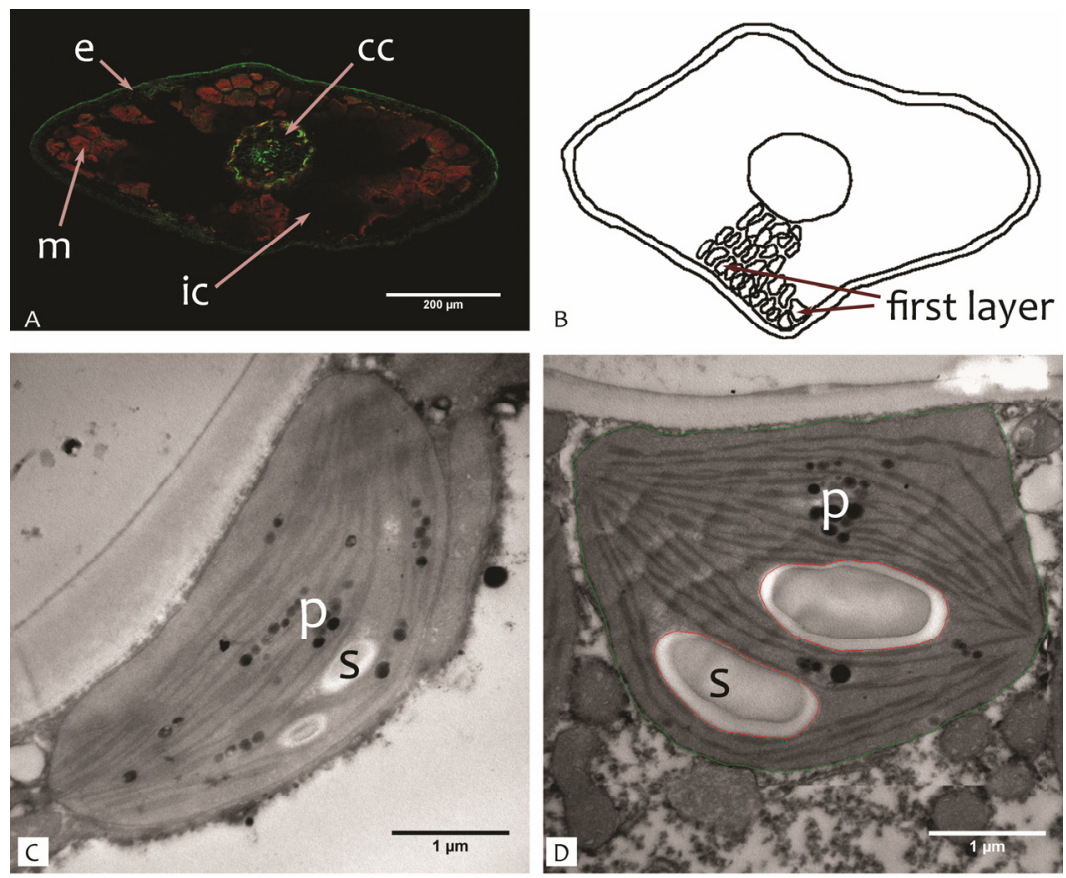

Fig. 1. Needle cross section and chloroplasts. A - Confocal image of needle cross section, bar $200 \mu \mathrm{m} ; \mathrm{m}-$ mesophyll with chloroplasts fluorescent in red, cc-central cylinder, ic-intercellular space, e-epidermis and hypodermis fluorescent in green. B - Scheme showing location of the first mesophyll layer in the needle cross section. C-TEM image of SUR sampled chloroplast from a deeper mesophyll layer, bar $1 \mu \mathrm{m}$. D-TEM image of chloroplast (encircled by a green line) from the first mesophyll layer, bar $1 \mu \mathrm{m}$; $s$-starch grains (encircled by a red line); $p$ - plastoglobuli.

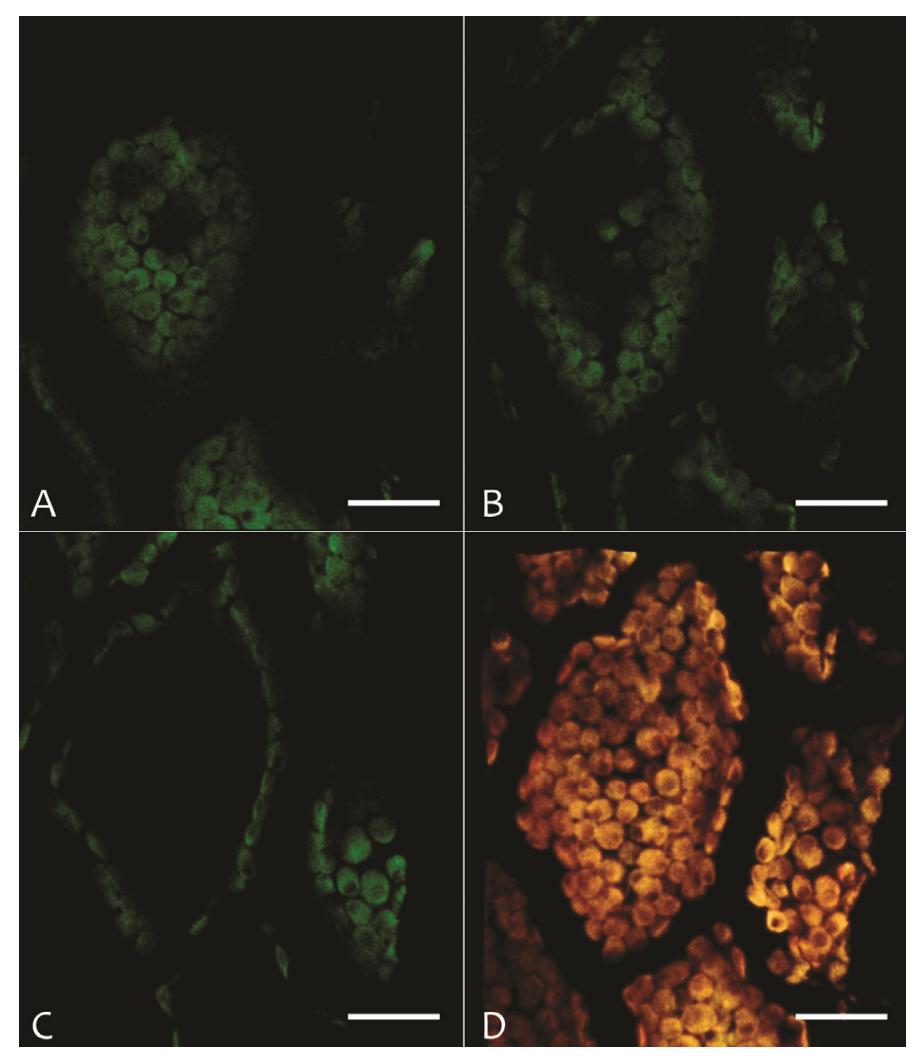

Fig. 2. Confocal images of Norway spruce mesophyll cells. A, B, C-single optical cross sections $1.95 \mu$ m apart with visible, autofluorescent chloroplasts (in green) showing that chloroplasts are located in the narrow cytoplasm layer below the cell membrane; D - volume rendering showing chloroplasts within $21 \mu \mathrm{m}$ thick layer. Bar $20 \mu \mathrm{m}$. 


\section{MATERIAL AND METHODS}

\section{EXPERIMENTAL SITE AND SAMPLE COLLECTION}

Norway spruce needles were collected from the experimental site of CzechGlobe AS CR in Moravskoslezské Beskydy (Beskid Mountains, Czech Republic), where the glass domes had controlled levels of $\mathrm{CO}_{2}$ concentration; with ambient atmospheric $\mathrm{CO}_{2}$ concentration $(\mathrm{AC})$ and elevated $\mathrm{CO}_{2}$ concentration $(\mathrm{EC}=$ 700 ppm) (Urban et al., 2001). The comparison was done separately in four combinations of $\mathrm{CO}_{2}$ concentration and irradiance: sun needles in ambient $\mathrm{CO}_{2}$ (AC sun), shade needles in ambient $\mathrm{CO}_{2}$ (AC shade), sun needles in elevated $\mathrm{CO}_{2}$ (EC sun) and shade needles in elevated $\mathrm{CO}_{2}$ (EC shade). Current-year sun $\left(3^{\text {rd }}\right.$ whorl) and shade ( $6^{\text {th }}$ whorl $)$ needles from both $\mathrm{CO}_{2}$ concentrations were collected in October 2011 from south- and south-west-facing branches of 11-yearold trees grown under these experimental conditions from the year 2005. The tree crowns were differentiated into sun and shade crown parts. For chloroplast counting, whole needles were frozen for confocal microscopy (Lhotáková et al., 2008). For ultrastructural analysis, segments (about $1 \mathrm{~mm}$ long) from the middle part of the needle were immediately fixed in 5\% glutaraldehyde $(\mathrm{v} / \mathrm{v})$ and transported to the laboratory.

\section{TRANSMISSION ELECTRON MICROSCOPY}

In the laboratory, the fixed samples were transferred into an automated microwave tissue processor Leica EM AMW (Leica Microsystems, Vienna, Austria). All steps of sample preparation were carried out automatically following the protocol according to Zechmann and Zellnig (2009). Samples were then manually transferred into the polymerization forms containing fresh Spurr's epoxy resin (Spurr, 1969) and polymerised at $70{ }^{\circ} \mathrm{C}$ for $48 \mathrm{~h}$.

Ultrathin sections $(70 \mathrm{~nm})$ were cut by an ultramicrotome (Leica EM UC7, Leica Microsystems, Vienna, Austria) and mounted on $1 \times 2 \mathrm{~mm}$ formvar coated slot grids. Images of needle cross sections and of individual chloroplasts were captured using transmission electron microscope JEOL JEM 1011 (JEOL, Tokyo, Japan).

For the analysis of chloroplast size and starch grain area and areal density, two different approaches were chosen. Firstly, chloroplasts from the first layer of mesophyll cells below the hypodermis (Fig. 1A) were chosen systematically, one from each third, fourth or fifth cell depending on the number of cells on a needle cross section, so that at least 7 chloroplasts per needle cross section were sampled. Secondly, chloroplasts from the whole needle cross sections (images captured at low magnification, $100 \times$ ) were chosen using stereological systematic uniform random (SUR) sampling (Gundersen and Jensen, 1987). At least 5 sampling fields were selected using our custom-made plug-in 'Rectangles' (Ellipse software, Vidito, Košice, Slovakia) (Fig. 3), and the first nearly median section of chloroplast from the middle of the sampling field was then captured for measurements (at 25,000 $\times$ magnification).

\section{LASER SCANNING CONFOCAL MICROSCOPY}

For laser scanning confocal microscopy, a cross section was made in the middle of the needle using a hand microtome. Series of optical sections were captured by Leica SP2 AOBS confocal laser scanning microscope (Ar laser excitation $488 \mathrm{~nm}$ and autofluorescence detection in green and red channels: 494-577 $\mathrm{nm}$ and $625-710 \mathrm{~nm}$ ). For chloroplast number estimation in the whole needle cross section, the procedure described in Kubínová et al. (2014) was applied: sampling fields were selected using systematic uniform random sampling (SUR, Fig. $3 \mathrm{~A}$ ) in the image captured by $10 \times$ objective (Fig. 1A). Detailed series were acquired by $63 \times$ objective. For chloroplast number estimation in the first mesophyll layer, 5 sampling fields around the needle in the image by $10 \times$ objective were selected using systematic sampling in the newly developed 'Object sampling' plug-in (Ellipse software, Vidito, Košice, Slovakia) (Fig. 3B). Detailed series were acquired by $63 \times$ objective (water immersion, NA 1.2, Fig. 2).

\section{STEREOLOGICAL MEASUREMENTS}

We compared chloroplast parameters acquired from the first mesophyll layer with those acquired from different positions on needle cross sections selected by SUR. In total, 215 chloroplasts from the first mesophyll layer and 183 chloroplasts selected by SUR were analysed to estimate the starch grain area, chloroplast area and starch areal density. For chloroplast number estimation, 100 and 104 series of confocal microscope images from the first mesophyll layer and selected by SUR, respectively, were analysed.

Starch grain cross-section size and starch areal density were determined on chloroplast median cross sections in TEM images using the method of interactive segmentation, based on drawing a line along the borders of the object under study using the software Ellipse (ViDiTo, Košice, SR). 
Chloroplast number was estimated by the optical disector method (Kubínová et al., 2014) from the series of optical sections acquired by the confocal microscope using $63 \times$ objective. For each needle, the number of chloroplasts per unit of needle volume was estimated by the formula (Sterio, 1984; Gundersen, 1986) (each term defined below):

$$
\operatorname{est}_{\text {Vneedle }}(\mathrm{chl})=\frac{\sum_{i=1}^{n} Q_{i}(\mathrm{chl})}{\sum_{i=1}^{n} P_{i}} \cdot \frac{p}{a \cdot h},
$$

est $N_{\text {Vneedle }}(\mathrm{chl})$ - estimated number of chloroplasts per unit of needle volume;

$Q_{i}(c h l)$ - sum of all sampled chloroplasts in all disector probes within a needle;

$\Sigma P_{i}$ - sum of all points falling within a needle in all 3D probes (for calculation needle volume in each probe) used for chloroplast counting;

$p$ - number of test points in a grid in a sampling frame used for chloroplast counting;

$a$ - area of disector sampling frame (base of the 3D probe) used for chloroplast counting;

$h$ - height of the disector probe used for chloroplast counting.

\section{STATISTICAL ANALYSES}

Two sample unequal variance t-tests were used for testing the hypothesis whether the first mesophyll layer is representative for the whole needle cross section. Chloroplast number in mesophyll, chloroplast cross-section area, starch grain cross-section size and starch grain areal density were compared for each combination of $\mathrm{CO}_{2}$ concentration and irradiance separately. The second step to test representativeness of first mesophyll layer one-way analysis of variance (ANOVA) and Tukey-Kramer Multiple-Comparison test was employed on two different datasets of chloroplast characteristics acquired from 1) the first mesophyll layer and 2) from SUR. These results of oneway ANOVA were compared to evaluate the representativeness of the first mesophyll layer.

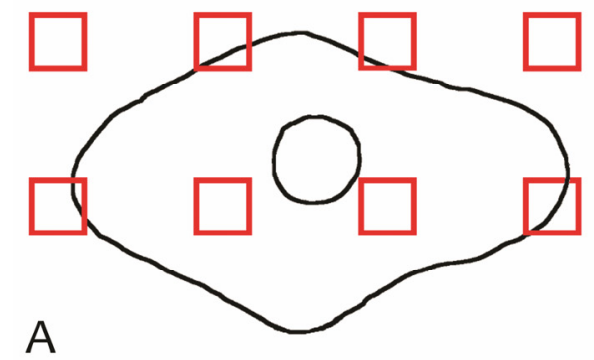

To evaluate the effects of $\mathrm{CO}_{2}$ and irradiance on chloroplast characteristics, two-way nested ANOVA was then employed using NCSS 9.0 software (NCSS, LCC Kaysville, Utah, USA). This type of ANOVA takes into account that sun and shade needles from one tree are not independent observations. The individual tree replicates were evaluated as a nested factor (subject variable), while $\mathrm{CO}_{2}$ treatment, and irradiance were used as fixed between factor variables. Differences were always considered as significant if $p<0.05$.

\section{RESULTS}

The time needed for chloroplast sampling by SUR was approximately six times longer than for selecting suitable chloroplasts from the first mesophyll layer.

In all four cases studied, the chloroplast number and chloroplast area estimated by evaluation of the first mesophyll layer were not significantly different from the chloroplast number and area measured in the whole needle cross section (Fig. 4 A, B). Thus, at this stage, we could not reject the hypothesis that chloroplast number and chloroplast area measurements in the first mesophyll cell layer were representative for the whole needle cross section. In three of four cases (AC shade, EC sun, EC shade) there was also no significant difference between both starch area and starch areal density assessed from the first mesophyll layer and the whole needle cross section (Fig. 4 C, D). However, both characteristics behaved differently in sun needles under ambient $\mathrm{CO}_{2}$ : starch area and starch areal density were significantly higher when assessed from the whole needle cross section in comparison with the first mesophyll layer (indicated by asterisks in Fig. 4 C, D). Regarding both the starch grain area and starch areal density, we thus cannot claim the first mesophyll layer as representative for the whole needle cross section. If we assume that the first mesophyll layer is representative for the whole needle regarding studied chloroplast characteristics, we should obtain identical results of

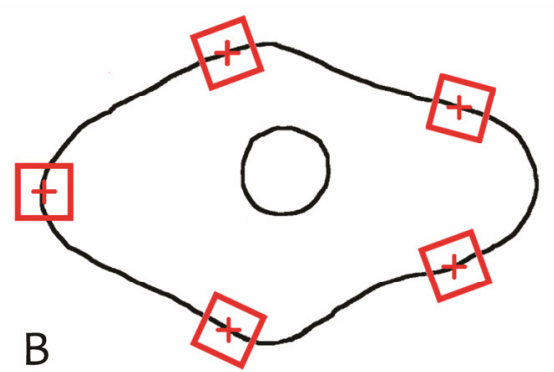

Fig. 3. Scheme of sampling of series of images by confocal microscopy on needle cross section. A-Systematic uniform random sampling using Ellipse plug-in 'Rectangles'. B-sampling in the first mesophyll layer using polygonal selection and Ellipse plug-in 'Object Sampling' to determine equidistant midpoints (crosses) of images captured using field rotation in the microscope. 
ANOVA from both datasets. However, this was not the case for all the characteristics studied (Table 1). The chloroplast number appeared to be significantly affected by $\mathrm{CO}_{2}$ concentration if tested on SUR sampled dataset. On the contrary, no effect of either $\mathrm{CO}_{2}$ concentration or irradiance was revealed if the dataset from the first mesophyll layer was used for analysis. In case of starch areal density, significant effect of both $\mathrm{CO}_{2}$ concentration and irradiance was detected for both datasets. However, the interaction of the environmental factors was significant only if the dataset from the first mesophyll layer was analysed. Therefore, we express an uncertainty regarding the representativeness of the first mesophyll layer for chloroplast number and starch areal density. On the other hand, both chloroplast area and starch grain area showed consistent ANOVA results for both datasets, with only the p-values slightly differing between the samplings (see p-values for $\mathrm{CO}_{2}$ concentration and interaction for starch grain area in Table 1).

Based on the comparisons presented above, we put in doubt the representativeness of the first mesophyll cell layer regarding three of four studied chloroplast characteristics: chloroplast number, starch grain area and starch areal density. The only characteristic, for which we did not clearly reject the first layer representativeness hypothesis, was the chloroplast area.

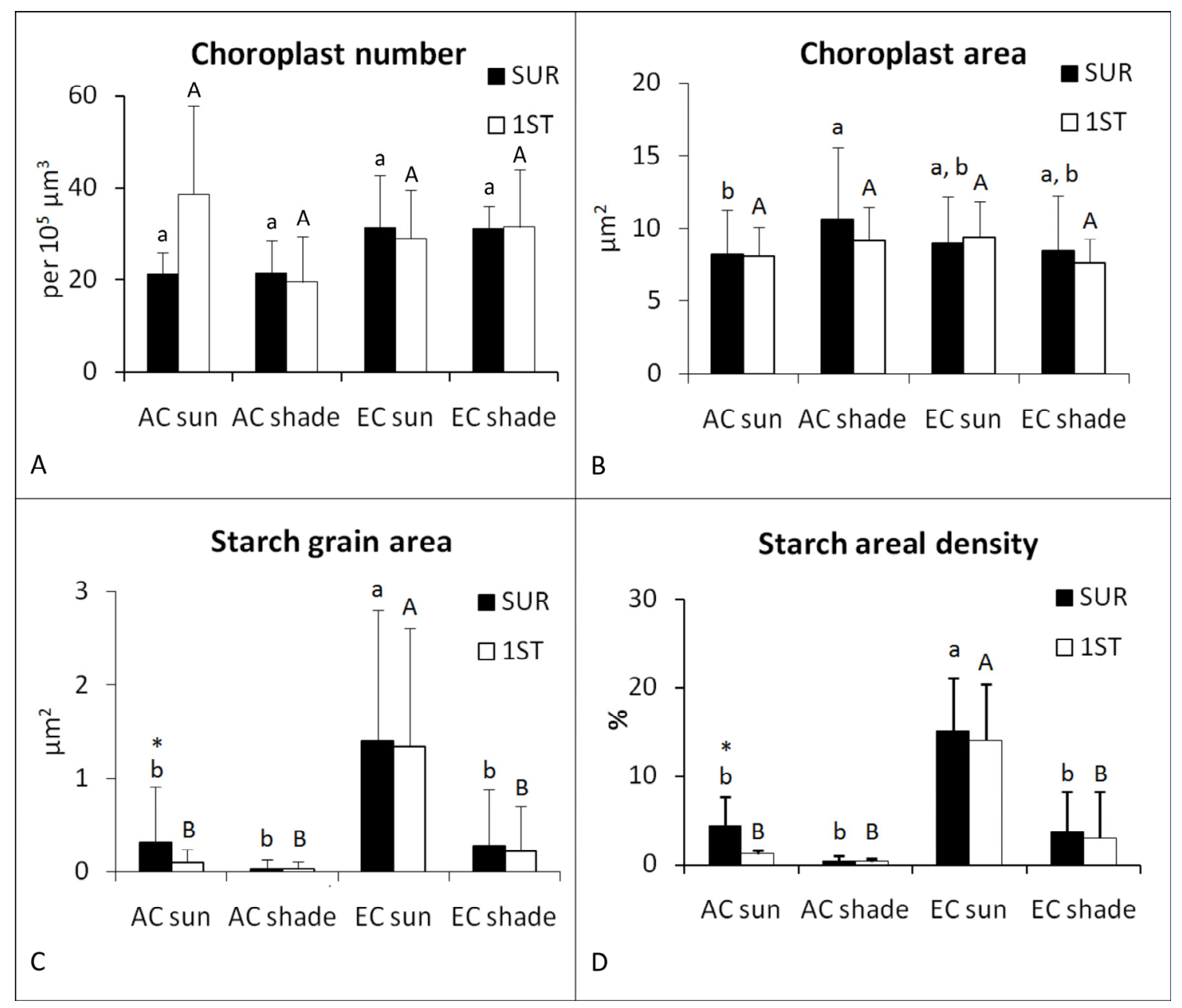

Fig. 4. Comparison of chloroplast characteristics sampled from the first mesophyll layer (1ST) and systematic uniform random sampling (SUR). A-Chloroplast number per mesophyll volume. B-Chloroplast cross-section area. $C$ - Starch grain cross-section area. D-Starch areal density on chloroplast cross section. AC-ambient $\mathrm{CO}_{2}$ concentration, EC - elevated $\mathrm{CO}_{2}$ concentration, black - SUR - systematically uniformly randomly sampled from the whole needle cross-section area, white - IST - sampled from the first layer of mesophyll. Bars - standard deviation.* - significant difference between SUR and the first layer within the same growth conditions at $p<0.05$ by two-sample t-test. Lower case letters above the bars - Tukey-Kramer MultipleComparison Test among SUR values, upper case letters above the bars - Tukey-Kramer Multiple-Comparison Test among IST values; bars having the same letter are not significantly different according to the test. 
Table 1. Effects of $\mathrm{CO}_{2}$ concentration, irradiance and interaction of both factors on chloroplast number per mesophyll volume and selected ultrastructural characteristics on median chloroplast cross section analysed by Two-way nested Analysis of Variance ( $p$-value). SUR - sampled systematically uniformly randomly from the whole needle cross-section area. First layer - sampled from the first layer of mesophyll. AC - ambient $\mathrm{CO}_{2}$ concentration, EC-elevated $\mathrm{CO}_{2}$ concentration. Significance: $*=p<0.05 ; * *=p<0.01$; n.s. $=$ not significant.

\begin{tabular}{l|l|cc|cc}
\hline \multirow{2}{*}{ Structural characteristic } & \multirow{2}{*}{ Factor } & \multicolumn{3}{|c|}{ SUR } & \multicolumn{2}{c}{ First layer } \\
\cline { 3 - 6 } & & p value & Significance & p value & Significance \\
\hline \multirow{3}{*}{ Chloroplast number } & Irradiance & 0.979370 & n.s. & 0.166354 & n.s. \\
& $\mathrm{CO}_{2}$ & 0.022420 & $*$ & 0.861250 & n.s. \\
& Interaction & 0.960103 & n.s. & 0.083487 & n.s. \\
\hline \multirow{3}{*}{ Chloroplast area } & Irradiance & 0.051896 & n.s. & 0.540956 & n.s. \\
& $\mathrm{CO}_{2}$ & 0.394268 & n.s. & 0.843852 & n.s. \\
& Interaction & 0.010480 & $*$ & 0.040781 & $*$ \\
\hline \multirow{3}{*}{ Starch grain area } & Irradiance & 0.004692 & $* *$ & 0.004037 & $* *$ \\
& $\mathrm{CO}_{2}$ & 0.004592 & $* *$ & 0.015830 & $*$ \\
& Interaction & 0.044399 & $*$ & 0.007329 & $* *$ \\
\hline \multirow{3}{*}{ Starch areal density } & Irradiance & 0.003792 & $* *$ & 0.001111 & $* *$ \\
& $\mathrm{CO}_{2}$ & 0.005008 & $* *$ & 0.013513 & $*$ \\
& Interaction & 0.093614 & n.s. & 0.002512 & $* *$ \\
\hline
\end{tabular}

Assuming that we cannot consider the first mesophyll layer to be fully representative for all studied chloroplast characteristics, emphasis was put on evaluation of the EC and irradiance effects based on the characteristics acquired by systematic uniform random sampling. A nested analysis of variance, which considered that sun and shade needles were col-lected from one tree, revealed significant effects of $\mathrm{CO}_{2}$ concentration on chloroplast number, starch grain area and starch areal density (Table 1). Chloroplasts were more abundant in needles from trees grown under EC in comparison with those grown under AC (Fig. 4 A), however, according to the multiple comparison test, the differences were not significant. The chloroplast area was not affected by $\mathrm{CO}_{2}$ concentration (Fig. 4 $\mathrm{B})$, but in the chloroplasts from sun needles in EC, the starch grain area and starch areal density were larger (Fig. 4 C, D). The irradiance was found to have no effect on either chloroplast number or chloroplast area (Table 1). However, there was a significant interaction between $\mathrm{CO}_{2}$ and irradiance. This corresponds with the result of the multiple comparison TukeyKramer test, which showed a significant difference in chloroplast area between sun and shade needles grown under ambient $\mathrm{CO}_{2}$ concentration but not in EC. Furthermore, the characteristics describing starch accumulation were strongly sensitive to irradiance. In EC, chloroplasts from the shade needles had lower starch grain area and starch areal density. According to the multiple comparison Tukey-Kramer test, both starch characteristics were significantly higher in sun needles from EC in comparison with the rest three $\mathrm{CO}_{2}$ and irradiance combinations (Fig. 4 C, D).

The same statistical analysis applied on the chloroplast characteristics assessed from the first mesophyll layer showed slightly different results than on SUR. The effect of EC on chloroplast number was not detected, probably due to high variance and higher values of this characteristic in sun needles grown in ambient $\mathrm{CO}_{2}$ concentration (Fig. 4A; Table 1). The effect of EC on starch grain area and starch areal density was significant, however slightly weaker in the first layer (see p-values for the first layer in Table 1). Lastly, the significance of the interaction between irradiance and $\mathrm{CO}_{2}$ concentration was more pronounced for starch grain area and starch areal density (see pvalues for the first layer in Table 1). Thus, for the majority of the studied structural characteristics, irradiance proved to be a stronger morphogenetic factor than EC.

\section{DISCUSSION}

Despite the clear importance of proper sampling in measurements of plant structure, this issue is often inadequately addressed in plant studies as pointed out recently by Kubínová et al. (2017). If the study aims for estimation of unbiased quantitative parameters for the whole plant organ, then SUR and stereological methods are recommended (West, 2012).

In this study, selected chloroplast characteristics measured on the same needle cross section sampled in the first mesophyll layer and sampled by SUR were 
in some cases significantly different. Thus, the first mesophyll layer was not always representative for every structural characteristic and every treatment. This is in agreement with the findings of Kivimäenpää and Sutinen (2007) who reported that mesophyll cells near the epidermis of four year old needles of Pinus sylvestris had smaller chloroplasts with lower area of starch grains than cells in the inner part of the needle. Furthermore, Senser et al. (1975) noticed in Picea abies that the chloroplasts in cells near to the epidermis had higher amounts of starch than cells near the central cylinder, according to the gradient in light intensity. Both studies confirm the variability of measured structural characteristics within the needle cross section.

Taking into account that measurements of chloroplast ultrastructure are extremely time consuming, we restricted our study to cross sections cut in the middle of the needle and not in a higher number of positions along the needle corresponding to a SUR sampling principle (for needle see e.g., Lhotáková et al., 2008). Even this restricted examination clearly reveals that sometimes chloroplast structural characteristics measurements give different results when evaluated from all layers of mesophyll cells in the needle than just in the first mesophyll layer. Unlike the evaluation of chloroplast ultrastructure where TEM is necessary, the measurement of plant anatomical characteristics is feasible by confocal microscopy (Albrechtová et al., 2007). This approach is much less time consuming than procedures necessary for ultrastructure measurements using TEM, and thus SUR sampling of needle sections can be recommended for proper chloroplast counting. This was shown by Kubínová et al. (2014) where the practical issues connected with the evaluation of thick needle sections by using confocal microscopy are discussed in detail.

In studies of chloroplast characteristics, description of sampling procedure on TEM images is often restricted to mere stating of how many cells were counted in a cross section, while further details of sampling within the section are omitted (Back and Huttunen, 1992; Oksanen et al., 2001; Bondada and Syvertsen, 2003). The SUR sampling is theoretically the best choice for unbiased measurement. However, it should be noted that using SUR on TEM images of conifer needles requires good fixation that can be challenging because of the thick, nearly impermeable cuticle, the extremely differentiated cell walls, with deposition of phenolics or even lignin (Soukupová et al., 2000), and a system of intercellular spaces (Meyberg, 1988; Ebel et al., 1990). Moreover, the size of whole cross sections of conifer needles (dimensions of approx. $2 \times 1 \mathrm{~mm}$ ) is rather large for ultra- thin sectioning, which adversely affects the quality of the sections (Hayat, 1970). Kivimäenpää et al. (2001, 2003) halved the needle longitudinally to cut the ultrathin sections from either adaxial or abaxial side of the needle, thus it was easier to get undistorted ultrathin sections. Preservation of chloroplast ultrastructure in conifers may also be improved by changing the buffers or embedding media (Ebel et al., 1990), by changing the molarity of buffers according to season (Soikkeli, 1980) or by using microwaves during sample processing (Zechman and Zellnig, 2009). Furthermore, even when SUR is used on TEM images, one should be aware, that the TEM image has a large depth of field, so that the single image may be in fact an overprojection. Therefore the use of electron tomography is recommended for more precise measurements (Vanhecke et al., 2007).

Another complication that makes SUR sampling more challenging in transmission electron microscopy is poststaining of the sections on slot grids. The slot grids are suitable for SUR sampling as they enable us to view whole large cross sections of the needle without interference of grid bars. Poststaining, if it is done manually on a drop of stain solutions (uranyl acetate followed by lead citrate), is technically challenging as the formvar coating on the slots is prone to ruptures. It is always possible to view sections without poststaining, as in this study, but it significantly decreases the observed contrast and resolution (Hayat, 1970; Ellis, 2007). Due to lower contrast in the deeper layers of mesophyll (Fig. 1C), we were able to quantify only the starch grain area but not the parameters of thylakoid membranes. A fully automated system for contrasting ultrathin sections (Yang et al., 2017) might solve this problem.

Lastly, SUR sampling can be much more time consuming depending on the equipment accessible for the study. In our case, SUR sampling was about six times more time consuming because of the need to pick the chloroplasts manually from the low contrast sections that were not poststained. However, the availability of the cutting edge equipment should certainly reduce or even diminish this difference (automated poststaining, automated acquisition).

Our study shows that chloroplast characteristics estimations acquired from the first mesophyll layers and SUR cannot always substitute each other. Based on our results, measurement of chloroplast characteristics from the first mesophyll layer slightly underestimates the effect of $\mathrm{CO}_{2}$ concentration. In the case of starch grain characteristics, this bias could mask $\mathrm{CO}_{2}$ concentration impact if only TEM analysis is used. If the possibility of using SUR for chloroplast 
evaluation is impeded by the extreme laboriousness or technical constraints, we recommend to combine TEM analysis with other physiological approaches, e.g., starch biochemical assessment (Mašková et al., 2017) or determination of photosystem activities and fluorescence parameters.

As discussed above, there are several objective constraints and challenges of using SUR in extensive studies based on TEM. In our case, we faced the difficulty in acquisition of high-quality and highcontrast ultrathin sections of the whole needle for SUR sampling and chloroplast selection. Considering the extreme laboriousness of sample preparation, the difficulties associated with technical processing and financial costs of TEM working hours, some simplifications of sampling principles are acceptable if the aim is for comparison of ultrastructural characteristics between different treatments.

The following discussion is based on results from SUR sampling. A trend to higher chloroplast number observed in the mesophyll of needles from trees grown under $\mathrm{EC}$ in comparison with those grown under $\mathrm{AC}$ agrees with studies on herbaceous plants and broadleaved trees (Oksanen et al., 2001; Wang et al., 2004; Oksanen et al., 2005; Teng et al., 2006). The effect of irradiance on chloroplast number is not always unambiguous, as it was in our case. In some previous studies, more chloroplasts were observed in sun than in shade leaves (Cui et al., 1991), and in high light compared with low light grown plants (Zhang et al., 2015). On the contrary, increased chloroplast number in shade conditions was also reported (Shao et al., 2014). Thus, the influence of irradiance on chloroplast number in conifers remains unclear.

Higher starch areal density and starch grain area in sun EC needles in comparison with sun AC needles is in agreement with previous findings in both leaves and needles in EC (Pritchard et al., 1997; Griffin et al., 2001; Oksanen et al., 2001; Eguchi et al., 2004; Liu et al., 2004; Sholtis et al., 2004; Liu et al., 2005; Teng et al., 2006; Onoda et al., 2007; Cabálková et al., 2008), and both starch characteristics were significantly higher in sun needles from EC in comparison with the other three $\mathrm{CO}_{2}$ and irradiance combinations. The difference may be explained by enhanced photosynthetic rate in EC (rev. Leakey et al., 2009), which may be more pronounced in sun needles leading to higher production of starch. Another explanation may be that the winter hardening process in the EC needles, sampled in October, was delayed as has been previously reported (Utriainen et al., 2000; Palomäki et al., 1996). In summary, the main influence of $\mathrm{CO}_{2}$ concentration, irradiance and their interaction was on the starch grain area and areal density, which were found to be largest in sun needles in EC.

\section{CONCLUSION}

Based on the results of our study, we conclude that the first mesophyll layer cannot be always considered as representative for chloroplast characteristics in the mesophyll on the whole cross section of Norway spruce needles. Therefore, if technically possible, we recommend the use of systematic uniform random sampling for the selection of examined cells and chloroplasts in conifers, which yields unbiased estimations of chloroplast ultrastructure, though depending on the equipment accessible it can be more time-consuming. However, in the case of limited time, technical equipment and resources in combination with large sample numbers in ecophysiological studies, we do not completely reject measuring the chloroplast ultrastructural characteristics from the first mesophyll layer if the aim is for comparison between different treatments. If such simplified sampling instead of SUR sampling is applied, it is advisable to combine the TEM analyses with different approaches to characterize the chloroplast function and to carefully consider and interpret the results.

\section{ACKNOWLEDGEMENTS}

We would like to thank the Global Change Research Centre of the Czech Academy of Sciences for providing us with the opportunity for plant cultivation and particularly to Dr. Otmar Urban and Dr. Miroslava Šprtová for their support and care for cultures We also thank to Mrs. Ivana Nováková for her excellent technical assistance with TEM sample preparation and to our colleague Mgr. Drahomíra Bartáková for a technical help. We gratefully acknowledge our colleague Dr. Kevin Jia-Jin Loo for language correction of the text. This study was supported by: Czech Science Foundation [P501/10/0340; 18-23702S]; Czech Academy of Sciences [RVO:67985823]; Charles University in Prague [SVV]; Ministry of Education, Youth and Sports of the Czech Republic [NPUI LO1417]; BioImaging Facility, Institute of Physiology - CzechBioImaging large RI project [LM2015062 funded by MEYS CR]; MEYS (CZ.02.1.01/0.0/0.0/16_013/ 0001775 Modernization and support of research activities of the national infrastructure for biological and medical imaging Czech-BioImaging funded by OP RDE), Project ERDF, OPPK BrainView CZ.2.16/ 3.1.00/21544, CESNET storage facilities provided under the programme "Projects of Large Research, Development, and Innovations Infrastructures" (CESNET LM2015042). 


\section{REFERENCES}

Albertsson PA, Andreasson E (2004). The constant proportion of grana and stroma lamellae in plant chloroplasts. Physiol Plantarum 121:334-42

Albrechtová J, Janáček J, Lhotáková Z, Radochová B, Kubínová L (2007). Novel efficient methods for measuring mesophyll anatomical characteristics from fresh thick sections using stereology and confocal microscopy: application on acid rain-treated Norway spruce needles. J Exp Bot 58:1451-61.

Anttonen S (1992). Changes in lipids of Pinus sylvestris needles exposed to industrial air pollution. Ann Bot Fenn:89-99.

Bäck J, Huttunen S (1992). Structural responses of needles of conifer seedlings to acid rain treatment. New Phytol 120:77-88.

Bondada BR, Syvertsen JP (2003). Leaf chlorophyll, net gas exchange and chloroplast ultrastructure in citrus leaves of different nitrogen status. Tree Physiol 23: 553-9.

Cabálková J, Přibyl J, Skládal P, Kulich P, Chmelík J (2008). Size, shape and surface morphology of starch granules from Norway spruce needles revealed by transmission electron microscopy and atomic force microscopy: effects of elevated $\mathrm{CO}_{2}$ concentration. Tree Physiol 28:1593-9.

Calfapietra C, Ainsworth EA, Beier C, De Angelis P, Ellsworth, DS, Godbold DL, et al. (2010). Challenges in elevated $\mathrm{CO}_{2}$ experiments on forests. Trends Plant Sci 15:5-10.

Cui M, Vogelmann T, Smith W (1991). Chlorophyll and light gradients in sun and shade leaves of Spinacia oleracea. Plant Cell Environ 14:493-500.

DeLucia EH, Day TA, Vogelman TC (1992). Ultraviolet-B and visible light penetration into needles of two species of subalpine conifers during foliar development. Plant Cell Environ 15: 921-9.

Demmig-Adams B, Muller O, Stewart JJ, Cohu CM, Adams WW (2015). Chloroplast thylakoid structure in evergreen leaves employing strong thermal energy dissipation. Journal of Photochemistry and Photobiology B: Biology 152:357-66.

Ebel B, Hamelmann U, Nieß C (1990). A rapid preparation method for ultrastructural investigations of conifer needles. J Microsc-Oxford 160:67-74.

Eguchi N, Fukatsu E, Funada R, Tobita H, Kitao M, Maruyama Y, et al. (2004). Changes in morphology, anatomy, and photosynthetic capacity of needles of Japanese larch (Larix kaempferi) seedlings grown in high $\mathrm{CO}_{2}$ concentrations. Photosynthetica 42:173-8.

Ellis EA (2007). Poststaining Grids for Transmission Electron Microscopy. In: Kuo J ed. Electron Microscopy. Ch. 6. Totowa: Humana Press, 97-106.
ESRL Global Monitoring Division, NOAA, U.S. Department of Commerce Trends in Atmospheric Carbon Dioxide - Recent Monthly Average Mauna Loa $\mathrm{CO}_{2}$. http://www.esrl.noaa.gov/gmd/ccgg/trends/index.html. Accessed 29 Jan 2018

Gebauer RL, Strain BR, Reynolds JF (1997). The effect of elevated $\mathrm{CO}_{2}$ and $\mathrm{N}$ availability on tissue concentrations and whole plant pools of carbon-based secondary compounds in loblolly pine (Pinus taeda). Oecologia 113:29-36.

Griffin KL, Anderson OR, Gastrich MD, Lewis JD, Lin G, Schuster W, et al. (2001). Plant growth in elevated $\mathrm{CO}_{2}$ alters mitochondrial number and chloroplast fine structure. P Natl Acad Sci-Biol 98:2473-8.

Gundersen H, Jensen E (1987). The efficiency of systematic sampling in stereology and its prediction. J MicroscOxford 147:229-63.

Gundersen H-JG (1986). Stereology of arbitrary particles. J Microsc-Oxford 143:3-45.

Günthardt-Goerg MS, McQuattie CJ, Maurer S, Frey B (2000). Visible and microscopic injury in leaves of five deciduous tree species related to cur, rent critical ozone levels. Environ Pollut 109:489-500.

Günthardt-Goerg MS, Vollenweider P (2015). Responses of beech and spruce foliage to elevated carbon dioxide, increased nitrogen deposition and soil type. AoB Plants 7:plv067.

Hayat MA (1970). Principles and Techniques of Electron Microscopy. New York: Van Nostrand Reinhold Company.

Jönsson AM, Kivimäenpää M, Stjernquist I, Sutinen S (2001). Frost hardiness in bark and needles of Norway spruce in southern Sweden. Trees 15:171-6.

Kainulainen P, Utriainen J, Holopainen JK, Oksanen J, Holopainen T (2000). Influence of elevated ozone and limited nitrogen availability on conifer seedlings in an open-air fumigation system: effects on growth, nutrient content, mycorrhiza, needle ultrastructure, starch and secondary compounds. Glob Change Biol 6:345-55.

Kivimäenpää M (2003). Cell Structural Changes in the Needles of Norway Spruce Exposed to Long-term Ozone and Drought. Ann Bot-London 92:779-93.

Kivimäenpää M, Selldén G, Sutinen S (2005). Ozoneinduced changes in the chloroplast structure of conifer needles, and their use in ozone diagnostics. Environ Pollut 137:466-75.

Kivimäenpää M, Sutinen S (2007). Microscopic structure of Scots pine (Pinus sylvestris (L.)) needles during ageing and autumnal senescence. Trees 21:645-59.

Kivimäenpää M, Riikonen J, Sutinen S, Holopainen T (2014). Cell structural changes in the mesophyll of Norway spruce needles by elevated ozone and elevated temperature in open-field exposure during cold acclimation. Tree Physiol 34:389-403. 
Kivimäenpää M, Sutinen S, Medin E-L, Karlsson PE, Selldén G (2001). Diurnal changes in microscopic structures of mesophyll cells of Norway spruce, Picea abies (L.) Karst., and the effects of ozone and drought. Ann Bot-London88:119-30.

Kubínová L, Kutík J (2007). Surface density and volume density measurements of chloroplast thylakoids in maize (Zea mays L.) under chilling conditions. Photosynthetica 45:481-8.

Kubínová L, Radochová B, Lhotáková Z, Kubínová Z, Albrechtová J (2017). Stereology, an unbiased methodological approach to study plant anatomy and cytology: past, present and future. Image Anal Stereol 35: 187-205.

Kubínová Z, Janáček J, Lhotáková Z, Kubínová L, Albrechtová J (2014). Unbiased estimation of chloroplast number in mesophyll cells: advantage of a genuine three-dimensional approach. J Exp Bot 65:609-20.

Kubínová Z, Janáček J, Lhotáková Z, Šprtová M, Kubínová L, Albrechtová J (2018). Norway spruce needle size and cross section shape variability induced by irradiance on a macro-and microscale and $\mathrm{CO}_{2}$ concentration. Trees 32:231-44.

Kutík J, Holá D, Kočová M, Rothová O, Haisel D, Wilhelmová $\mathrm{N}$, et al. (2004). Ultrastructure and dimensions of chloroplasts in leaves of three maize (Zea mays L.) inbred lines and their F1 hybrids grown under moderate chilling stress. Photosynthetica 42: 447-55.

Leakey ADB, Ainsworth EA, Bernacchi CJ, Rogers A, Long SP, Ort DR (2009). Elevated $\mathrm{CO}_{2}$ effects on plant carbon, nitrogen, and water relations: six important lessons from FACE. J Exp Bot 60:2859-76.

Lepeduš H, Cesar V, Ljubešić N (2001). Chloroplast ultrastructure and chlorophyll levels in vegetative buds and needles of Norway spruce (Picea abies L. Karst.). Periodicum biol (Zagreb) 103:61-5.

Lhotáková Z, Albrechtová J, Janáček J, Kubínová L (2008). Advantages and pitfalls of using free-hand sections of frozen needles for three-dimensional analysis of mesophyll by stereology and confocal microscopy. J MicroscOxford 232:56-63.

Lhotáková Z, Urban O, Dubánková M, Cvikrová M, Tomášková I, Kubínová L, et al. (2012). The impact of long-term $\mathrm{CO}_{2}$ enrichment on sun and shade needles of Norway spruce (Picea abies): Photosynthetic performance, needle anatomy and phenolics accumulation. Plant Sci 188:60-70.

Lin JX, Jach ME, Ceulemans R (2001). Stomatal density and needle anatomy of Scots pine (Pinus sylvestris) are affected by elevated $\mathrm{CO}_{2}$. New Phytol 150:665-74.

Liu X, Kozovits AR, Grams TE, Blaschke H, Rennenberg H, Matyssek R (2004). Competition modifies effects of enhanced ozone/carbon dioxide concentrations on carbohydrate and biomass accumulation in juvenile Norway spruce and European beech. Tree Physiol 24: 1045-55.
Liu X-P, Grams TEE, Matyssek R, Rennenberg H (2005). Effects of elevated $\mathrm{pCO}_{2}$ and/or $\mathrm{pO}_{3}$ on $\mathrm{C}-, \mathrm{N}-$, and $\mathrm{S}$ metabolites in the leaves of juvenile beech and spruce differ between trees grown in monoculture and mixed culture. Plant Physiol Bioch 43:147-54.

Mašková $\mathrm{P}$, Radochová $\mathrm{B}$, Lhotáková $\mathrm{Z}$, Michálek J, Lipavská H (2017). Nonstructural carbohydrate-balance response to long-term elevated $\mathrm{CO}_{2}$ exposure in European beech and Norway spruce mixed cultures: biochemical and ultrastructural responses. Can J Forest Res 47:1488-94.

Meyberg M (1988). Selective staining of fungal hyphae in parasitic and symbiotic plant-fungus associations. Histochemistry 88:197-9.

Oksanen E, Riikonen J, Kaakinen S, Holopainen T, Vapaavuori E (2005). Structural characteristics and chemical composition of birch (Betula pendula) leaves are modified by increasing $\mathrm{CO}_{2}$ and ozone. Glob Change Biol 11:732-48.

Oksanen E, Sober J, Karnosky DF (2001). Impacts of elevated $\mathrm{CO}_{2}$ and/or $\mathrm{O}_{3}$ on leaf ultrastructure of aspen (Populus tremuloides) and birch (Betula papyrifera) in the Aspen FACE experiment. Environ Pollut 115:43746.

Onoda Y, Hirose T, Hikosaka K (2007). Effect of elevated $\mathrm{CO}_{2}$ levels on leaf starch, nitrogen and photosynthesis of plants growing at three natural $\mathrm{CO}_{2}$ springs in Japan. Ecol Res 22:475-84.

Palomäki V, Laitinen K, Holopainen T, Kellomäki S (1996). First-year results on the effects of elevated atmospheric $\mathrm{CO}_{2}$ and $\mathrm{O}_{3}$ concentrations on needle ultrastructure and gas exchange responses of Scots pine saplings. Silva Fenn 30:123-34.

Parkhurst DF, Wong S-C, Farquhar GD, Cowan IR (1988). Gradients of intercellular $\mathrm{CO}_{2}$ levels across the leaf mesophyll. Plant Physiol 86:1032-37.

Polák T, Rock BN, Campbell PE, Soukupová J, Solcová B, Zvára K, et al. (2006). Shoot growth processes, assessed by bud development types, reflect Norway spruce vitality and sink prioritization. Forest Ecol Manag 225:337-48.

Pritchard SG, Peterson CM, Prior SA, Rogers HH (1997). Elevated atmospheric $\mathrm{CO}_{2}$ differentially affects needle chloroplast ultrastructure and phloem anatomy in Pinus palustris: Interactions with soil resource availability. Plant Cell Environ 20:461-71.

Räisänen T, Ryyppö A, Julkunen-Tiitto R, Kellomäki S (2008). Effects of elevated $\mathrm{CO}_{2}$ and temperature on secondary compounds in the needles of Scots pine (Pinus sylvestris L.). Trees 22:121-35.

Sallas L, Luomala E-M, Utriainen J, Kainulainen P, Holopainen JK (2003). Contrasting effects of elevated carbon dioxide concentration and temperature on Rubisco activity, chlorophyll fluorescence, needle ultrastructure and secondary metabolites in conifer seedlings. Tree Physiol 23:97-108. 
Senser M, Schötz F, Beck E (1975). Seasonal changes in structure and function of spruce chloroplasts. Planta 126:1-10.

Shao Q, Wang H, Guo H, Zhou A, Huang Y, Sun Y, et al. (2014). Effects of Shade Treatments on Photosynthetic Characteristics, Chloroplast Ultrastructure, and Physiology of Anoectochilus roxburghii. PLoS ONE 9: e85996.

Sharkova VE, Bubolo LS (1996). Effect of heat stress on the arrangement of thylakoid membranes in the chloroplasts of mature wheat leaves. Russ J Plant Physl+ 43: 358-65.

Sholtis JD, Gunderson CA, Norby RJ, Tissue DT (2004). Persistent stimulation of photosynthesis by elevated $\mathrm{CO}_{2}$ in a sweetgum (Liquidambar styraciflua) forest stand. New Phytol 162:343-54.

Siefermann-Harms D, Boxler-Baldoma C, von Wilpert K, Heumann H-G (2004). The rapid yellowing of spruce at a mountain site in the Central Black Forest (Germany). Combined effects of $\mathrm{Mg}$ deficiency and ozone on biochemical, physiological and structural properties of the chloroplasts. J Plant Physiol 161:423-37.

Smith WK, Vogelmann TC, DeLucia EH, Bell DT, Shepherd KA (1997). Leaf form and photosynthesis. Bioscience 47:785-93.

Soikkeli S (1978). Seasonal changes in mesophyll ultrastructure of needles of Norway spruce (Picea abies). Can J Botany 56:1932-40.

Soikkeli S (1980). Ultrastructure of the mesophyll in Scots pine and Norway spruce: seasonal variation and molarity of the fixative buffer. Protoplasma 103:241-52.

Soukupová J, Cvikrová M, Albrechtová J, Rock BN, Eder J (2000). Histochemical and biochemical approaches to the study of phenolic compounds and peroxidases in needles of Norway spruce (Picea abies). New Phytol 146:403-14.

Spurr AR (1969). A low-viscosity epoxy resin embedding medium for electron microscopy. J Ultra Struct R 26: $31-43$.

Sterio D (1984). The unbiased estimation of number and sizes of arbitrary particles using the disector. J MicroscOxford 134:127-36.

Sun ZP, Li TL, Liu YL (2011). Effects of elevated $\mathrm{CO}_{2}$ applied to potato roots on the anatomy and ultrastructure of leaves. Biol plant 55: 675.

Teng N, Wang J, Chen T, Wu X, Wang Y, Lin J (2006). Elevated $\mathrm{CO}_{2}$ induces physiological, biochemical and structural changes in leaves of Arabidopsis thaliana. New Phytol 172:92-103.

Urban O, Janouš D, Pokorný R, Markova I, Pavelka M, Fojtík Z, et al. (2001). Glass Domes with Adjustable
Windows: A Novel Technique for Exposing Juvenile Forest Stands to Elevated $\mathrm{CO}_{2}$ Concentration. Photosynthetica 39:395-401.

Utriainen J, Janhunen S, Helmisaari H-S, Holopainen T (2000). Biomass allocation, needle structural characteristics and nutrient composition in Scots pine seedlings exposed to elevated $\mathrm{CO}_{2}$ and $\mathrm{O}_{3}$ concentrations. Trees $14: 475-84$

Valkama E, Kivimäenpää M, Hartikainen H, Wulff A (2003). The combined effects of enhanced UV-B radiation and selenium on growth, chlorophyll fluorescence and ultrastructure in strawberry (Fragaria $\times$ ananassa) and barley (Hordeum vulgare) treated in the field. Agr Forest Meteorol 120:267-78.

Vanhecke D, Studer D, Ochs M (2007). Stereology meets electron tomography: Towards quantitative 3D electron microscopy. J Struct Biol 159:443-50.

Velikova V, Tsonev T, Barta C, Centritto M, Koleva D, Stefanova M, et al. (2009). BVOC emissions, photosynthetic characteristics and changes in chloroplast ultrastructure of Platanus orientalis L. exposed to elevated $\mathrm{CO}_{2}$ and high temperature. Environ Pollut 157:262937.

Wang X, Anderson OR, Griffin KL (2004). Chloroplast numbers, mitochondrion numbers and carbon assimilation physiology of Nicotiana sylvestris as affected by $\mathrm{CO}_{2}$ concentration. Environ Exp Bot 51:21-31.

West MJ (2012). Only total quantities will do: Beware the reference trap. In: Basic stereology for biologists and neuroscientists. Ch. 1.7. New York, Cold Spring Harbor Laboratory Press, 8-9.

Wheeler WS, Fagerberg WR (2000). Exposure to low levels of photosynthetically active radiation induces rapid increases in palisade cell chloroplast volume and thylakoid surface area in sunflower (Helianthus annuus L.). Protoplasma 212:38-45.

Wulff A, Ahonen J, Kärenlampi L (1996). Cell ultrastructural evidence of accelerated ageing of Norway spruce needles in industrial areas. New Phytol 133:553-61.

Yang R, Wang S, Wang J, Luo X, Zhao W, Zhang Q, et al. (2017). Comparison of manual and automatic processing of biological samples for electron microscopy. Microsc Res Techniq 80:570-77.

Zechmann B, Zellnig G (2009). Microwave-assisted rapid plant sample preparation for transmission electron microscopy. J Microsc-Oxford 233:258-68.

Zhang LX, Guo QS, Chang QS, Zhu ZB, Liu L, Chen YH (2015). Chloroplast ultrastructure, photosynthesis and accumulation of secondary metabolites in Glechoma longituba in response to irradiance. Photosynthetica 53:144-53. 